\title{
Is There a Role for Simultaneous Hepatic and Colorectal Resections? A Contemporary View from NSQIP
}

\author{
Mathias Worni • Christopher R. Mantyh • \\ Igor Akushevich • Ricardo Pietrobon • Bryan M. Clary
}

Received: 30 April 2012 / Accepted: 25 July 2012 /Published online: 13 September 2012

(C) 2012 The Society for Surgery of the Alimentary Tract

\begin{abstract}
Introduction The optimal timing of primary and metastatic tumor management in patients with synchronous hepatic colorectal metastases remains controversial. We aimed to compare perioperative outcomes of simultaneous colorectal/liver resection (SCLR) with isolated resections utilizing a national clinical database.

Methods NSQIP data from 2005 to 2009 were examined to construct risk-adjusted generalized linear models and to calculate group-specific predicted estimates. These were used to compare 30-day perioperative outcomes among patients undergoing SCLR with colorectal (CR) and liver resections (LR) only in patients with metastatic colorectal cancer.

Results A total of 3,983 patients were identified, who underwent SCLR (192), LR $(1,857)$, or CR $(1,934)$. Rectal resection was performed in $45(23.4 \%)$ SCLR patients and $269(13.9 \%)$ CR patients $(p<0.001)$. Major hepatectomy was performed in 69 (35.9\%) SCLR patients and 774 (41.7\%) LR patients $(p=0.12)$. Median adjusted operation time (SCLR: $273 \mathrm{~min}, 95 \% \mathrm{CI}: 253-295$; CR: 172, CI: 168-177; LR: 222, CI: 217-228; $p<0.001$ ) and median adjusted length of hospital stay (SCLR: 9.5 days, CI: 8.8-10.4; CR: 8.1, CI: 7.9-8.3; LR: 6.4, CI: 6.3-6.6; $p<0.001$ ) were longer for SCLR compared to CR and LR. Adjusted predicted risks for at least one postoperative complication were higher in SCLR (36.3 \%) than in CR (26.6 \%) and LR (19.8 \%) ( $p<0.003)$, mostly due to infectious/ cardiopulmonary issues.

Discussion In SCLR patients, the risk of 30-day adverse outcomes is higher, and median operation time as well as length of hospital stay is longer compared to CR and LR patients. However, the expected combined morbidities of staged procedures though likely favor SCLR in carefully selected patients undergoing even complex hepatic and colorectal resections and should be considered.
\end{abstract}

Keywords Hepatic resection - Liver resection - Colorectal cancer $\cdot$ Metastases

Part of the manuscript was presented at the annual meeting of the Society of Surgery of the Alimentary Tract (SSAT) Mai 2012 in San Diego.

M. Worni · C. R. Mantyh · R. Pietrobon • B. M. Clary $(\bowtie)$ Department of Surgery, Duke University Medical Center, Durham, NC 27710, USA

e-mail: bryan.clary@duke.edu

I. Akushevich

Center for Population Health and Aging, Duke University,

Durham, NC, USA

\section{Introduction}

Colorectal cancer is one of the most prevalent malignancies throughout the world and especially in the USA. ${ }^{1}$ Among those patients, about $20 \%$ present at diagnosis already with synchronous liver metastases, while 30-40\% develop hepatic metastases in the follow-up., ${ }^{2,3}$ Patients with unresected metastasis of colorectal cancer have a poor 5-year survival of less than $5 \%,{ }^{4}$ while patients with completely resected colorectal cancer can achieve a 5-year survival rate of up to $58 \%$ even after partial hepatectomy. ${ }^{5-9}$ Historically, patients were managed with resection of the primary and subsequent systemic therapy prior to consideration of hepatectomy in order to best select patients for this complex and 
potentially morbid procedure. However, recent evidence suggests that simultaneous colorectal/liver resection (SCLR) of the primary tumor and the liver metastases might be an attractive option, ${ }^{10}$ but the safety of this strategy has not been explored outside of modest single or multiinstitutional experiences.

Significant progress in the field of liver surgery including resection techniques, perioperative care, preoperative imaging, and better systemic therapies has helped to solidify and expand the role of partial hepatectomy in the management of patients with colorectal metastases. Although high-volume centers routinely report perioperative mortality rates of $1-$ $3 \%,{ }^{10-13}$ broader datasets continue to report an overall mortality for major hepatectomies in the USA of approximately $7 \% .{ }^{14}$ Overall, severe morbidity rates of approximately $20-30 \%$ are routinely reported and highlight the need to identify ways in which to improve perioperative outcomes. The rising attractiveness of SCLR is supported by the fact that overall survival comparing simultaneous and staged resections of liver metastases shows comparable outcomes in single small multicenter studies. ${ }^{15-20}$

The primary goal of this investigation was to compare 30-day perioperative outcomes in patients with metastatic colorectal cancer undergoing SCLR with isolated resections. Using a more inclusive national clinical database, we sought to achieve a more generalizable picture of the short-term outcomes for SCLR.

\section{Methods}

The Institutional Review Board (IRB) at Duke University approved the study protocol. This secondary data analysis was conducted using the publicly available American College of surgeons National Surgical Quality Improvement Program (ACS-NSQIP) from 2005 to 2009. The ACSNSQIP data collect information of over 200 hospitals on a volunteer basis and capture 240 variables including data on preoperative risk factors, intraoperative data, and 30-day postoperative morbidity and mortality. In the year 2009, 336,190 patient records were collected. Patient data are extracted through trained personnel, and Inter-Rater Reliability Audits are performed on a regular basis.

We included patients 18 years and older diagnosed with metastatic colorectal cancer who underwent a tumordirected resection and patients undergoing liver resection for metastatic disease. We then grouped the patients into three distinct groups: (1) isolated colorectal resection for metastatic colorectal cancer only (CR), (2) isolated liver resection for secondary cancer to the liver (LR), and (3) simultaneous colorectal resection and a liver resection due to colorectal cancer (SCLR). Patient identification was performed through a two-step approach. First, we identified colorectal cancer patients and patients with secondary cancer to the liver through the following ICD-9-CM diagnosis codes (International Classification of Diseases, 9th Revision, Clinical Modification): 153.x (malignant neoplasm of the colon); 154, 154.0, and 154.1 (malignant neoplasm of the rectum, rectosigmoid junction); and 197.7 (secondary cancer to the liver). Second, patients undergoing tumordirected resection were identified through the following CPT codes (Current Procedural Terminology): (1) colon resection (44140, 44141, 44143-44147, 44150/1, 44155, 44157/8, 44160, 44204-44208, and 44210-44212), (2) rectal resection (45110-45114, 45119, 45121, 45123, 45126, 45395, and 45397), and (3) liver resection (47120, 47122, 47125, and 47130). Patients undergoing an intraoperative liver biopsy only, patients admitted as emergency cases, and patients with impaired functional status were excluded from this analysis. For subgroup analyses, we further divided LR and SCLR patients into major (resection of at least three liver segments) and minor liver resections.

Patient baseline characteristics from ACS-NSQIP were extracted as follows: gender, ethnicity (white, black, Hispanic, other), age, body mass index (BMI, calculated from height and weight), alcohol and smoking status, neoadjuvant radio- (last 90 days) or chemotherapy (last 30 days), diabetes (no, oral medication, insulin dependency), COPD, relevant heart disease (congestive heart failure, myocardial infarction, percutaneous coronary intervention, history of angina pectoris), arterial hypertension requiring medication, peripheral arterial disease, dialysis, central nervous system disease (impaired sensorium, coma $>24 \mathrm{~h}$, hemiplegia, history of transient ischemic attacks, cerebrovascular insult with and without neurological deficit, tumor involving the central nervous system, paraplegia, quadriplegia), dyspnea, weight loss $>10 \%$ in the last 6 months, and ASA score (grouped: $1 / 2,3$, or higher). We also extracted and grouped the following laboratory values: albumin $(<3.0, \geq 3.0 \mathrm{~g} / \mathrm{dl})$, creatinine $(\leq 1.5,>1.5 \mathrm{mg} / \mathrm{dl})$, and sodium $(<136$, $\geq 136 \mathrm{mmol} / \mathrm{l}$ ). Anemia was defined as a hematocrit $<36.1 \%$ for males and $<40.7 \%$ for females.

The following perioperative outcomes were extracted: superficial surgical site infection (SSI), deep incisional SSI/wound disruption, organ space SSI, any cardiopulmonary complication (pneumonia, unplanned intubation, longer than $48 \mathrm{~h}$ on mechanical ventilation, cardiac arrest requiring reanimation, myocardial infarction), any renal complication (progressive renal failure, acute renal failure, urinary tract infection), any CNS complication (stroke, coma $>24 \mathrm{~h}$ ), any thrombo-embolic event (deep vein thrombosis/thrombophlebitis, pulmonary embolism), and any septic complication (sepsis, septic shock). The number of individual complications was calculated from the aforementioned adverse outcomes and continuously grouped from 0 to 6 or higher. Data on mortality, return to the operating 
room, and if intraoperative red blood cell products were given were also collected. We also extracted the following periods: duration from anesthesia start to surgery start, duration from surgery stop to anesthesia stop, duration of patients in the operating room, total duration of anesthesia and operation, and length of hospital stay.

\section{Statistical Analysis}

Baseline characteristics among SCLR, CR, and LR patients were compared using ANOVA for continuous and chisquare test for categorical variables.

We compared frequencies of perioperative outcomes among SCLR, CR, and LR, unadjusted analyses using chisquare test for categorical and linear regression for continuous outcomes. Given the right skewness of the periodic outcomes, we used log transformation. The estimates were then re-transformed using the exponential formula, and median values as well as the $95 \%$ confidence intervals are provided. ${ }^{21}$ Adjusted comparisons of dichotomous and continuous perioperative outcomes among SCLR, CR, and LR patients were performed using multivariable logistic and linear regression models, respectively. Adjustment was performed using covariates defined a priori including defined covariates: gender, ethnicity, age, BMI, smoking status, number of comorbidities, dyspnea, ASA score, preoperative weight loss, preoperative radio-/chemotherapy, hypoalbuminemia $(<3.0 \mathrm{~g} / \mathrm{dl})$, hypercreatinemia $(>1.5 \mathrm{mg} / \mathrm{dl})$, anemia (hematocrit $<36.1 \%$ for males and $<40.7 \%$ for females), and hyponatremia $(<136 \mathrm{mmol} / \mathrm{l})$. Multivariable-adjusted predicted risks of experiencing one of the dichotomous perioperative outcomes for patients undergoing SCLR, $\mathrm{CR}$, and LR were calculated. The comparison among the number of individual postoperative complications across SCLR, CR, and LR was performed using a count model with a negative binomial regression distribution family. Negative binomial regression performed better than the Poisson regression and the zero-inflated negative binomial regression according to the Bayesian information criterion (BIC).

Subgroup analyses for main outcomes between SCLR and LR for major and minor hepatectomies were performed using the same analytical strategy as described previously. In addition, we assessed predictors of postoperative adverse outcomes among SCLR patients using unadjusted and multivariable-adjusted logistic regression analyses having at least postoperative complication as the outcome variable.

\section{Sensitivity Analyses}

The laboratory variables (albumin, creatinine, hematocrit, and sodium) demonstrated overall a missing rate of $19.2 \%$. We therefore performed sensitivity analyses excluding the laboratory variables as covariates from all adjusted analyses comparing the short-term postoperative outcomes.

A significance level (alpha) of 0.05 was used for all analyses. $P$-values $(p)$ for all tests were two-sided. Results of regression analysis are provided as odds ratio (OR) and $95 \%$ confidence intervals (CI). All statistical calculations were performed using Stata/SE version 11.2 (Stata Corporation, College Station, TX).

\section{Results}

Data from a total of 3,983 patients with metastatic colorectal cancer disease were evaluated, $192(4.8 \%)$ patients were in the SCLR, 1,934 (48.6\%) in the CR, and 1,857 (46.6\%) in the LR group. Most patients were male $(n=2,133,53.6 \%)$ and white $(n=3,089,77.6 \%)$, the overall mean age was 61.5 years (SD: 12.7), and the mean BMI was $27.6 \mathrm{~kg} / \mathrm{m}^{2}$ (SD: 6.3) (Table 1). More SCLR patients underwent a rectal resection $(n=45 ; 23.4 \%)$ than CR patients $(n=269 ; 13.9 \%)(p<0.001)$. No difference in relation to the rate of major hepatectomies was detected among SCLR and LR patients $(p=0.12)$.

\section{Unadjusted Analyses}

In unadjusted analyses, the three groups differed for the following perioperative outcomes: superficial SSI, deep incisional SSI, organ space SSI, any SSI, renal complications, septic complications, number of postoperative complications, use of red blood cells, rate of return to the operating room, and mortality (Table 2). Compared to SCLR patients, the time duration from the beginning of anesthesia to the start of surgery as well as the duration from the end of surgery to the end of anesthesia was shorter in the CR group, while no such difference was detected compared to the LR group (Table 3). The median operation time was longer in SCLR (304 min) than in CR (165 min) and LR (226 min), $p<0.001$ for both analyses. Median length of stay was longer in SCLR (9.34 days) than in CR (8.29 days) and LR (6.13 days), $p<0.006$ for both analyses.

\section{Adjusted Analyses and Predicted Values}

In adjusted analyses, the odds of having any surgical site infection were significantly lower for CR (OR: 0.62, CI: $0.41-0.94, p=0.025)$ and for LR (OR: 0.33, CI: 0.22-0.51, $p<0.001$ ) compared to SCLR (Table 4). The sum of the adjusted predicted risks for CR and LR was similar to the predicted risk for SCLR. In addition, lower odds for cardiopulmonary complications for CR (OR: $0.38, \mathrm{CI}$ : $0.21-0.68$, $p=0.001)$ and LR (OR: 0.47, CI: 0.26-0.83, $p=0.009$ ) were found compared to SCLR, as well as lower septic complications (CR; OR: 0.43, CI: 0.26-0.71, $p=0.001$; LR; OR: 
Table 1 Baseline patient characteristics

\begin{tabular}{|c|c|c|c|c|c|}
\hline \multirow{2}{*}{$\begin{array}{l}\text { Table } 1 \text { Baseline patient } \\
\text { characteristics }\end{array}$} & & SCLR & $\mathrm{CR}$ & LR & $p$-value overall \\
\hline & Total number & $192(4.8 \%)$ & $1,934(48.6 \%)$ & $1,857(46.6 \%)$ & \\
\hline & \multicolumn{5}{|l|}{ Gender } \\
\hline & Male & $118(61.5)$ & $994(51.4)$ & $1,021(55.0)$ & 0.007 \\
\hline & Female & $74(38.5)$ & $940(48.6)$ & $836(45.0)$ & \\
\hline & \multicolumn{5}{|l|}{ Ethnicity } \\
\hline & White & $151(78.7)$ & $1,440(74.5)$ & $1,498(80.7)$ & $<0.001$ \\
\hline & Black & $15(7.8)$ & $214(11.1)$ & $141(7.6)$ & \\
\hline & Hispanic & $5(2.6)$ & $73(3.8)$ & $41(2.2)$ & \\
\hline & Other/missing & $21(10.9)$ & $207(10.7)$ & $177(9.5)$ & \\
\hline & Age (mean, SD) & $58.4(10.8)$ & $63.5(13.5)$ & $59.7(11.7)$ & $<0.001$ \\
\hline & BMI $\left(\mathrm{kg} / \mathrm{m}^{2}\right)$ (mean, SD) & $26.9(5.5)$ & $27.1(6.3)$ & $28.2(6.2)$ & 0.067 \\
\hline & Colectomies & $147(76.6)$ & $1,665(86.1)$ & - & $<0.001$ \\
\hline & Rectal resection & $45(23.4)$ & $269(13.9)$ & - & \\
\hline & Minor hepatectomy & $123(64.1)$ & - & $1,083(58.3)$ & 0.12 \\
\hline & Major hepatectomy ( $\geq$ three segments) & $69(35.9)$ & - & $774(41.7)$ & \\
\hline & Alcohol—yes & $9(4.7)$ & $83(4.3)$ & $63(3.4)$ & 0.30 \\
\hline & Smoking-yes & $51(26.6)$ & $358(18.5)$ & $227(12.2)$ & $<0.001$ \\
\hline & Neoadjuvant radiotherapy (last 90 days) & $40(20.8)$ & $194(10.0)$ & $25(1.4)$ & $<0.001$ \\
\hline & Neoadjuvant chemotherapy (last 30 days) & $29(15.1)$ & $148(7.7)$ & $265(14.3)$ & $<0.001$ \\
\hline & \multicolumn{5}{|l|}{ Diabetes } \\
\hline & No & $172(89.6)$ & $1,660(85.8)$ & $1,599(86.1)$ & 0.69 \\
\hline & Oral medication & $13(6.8)$ & $187(9.7)$ & $179(9.6)$ & \\
\hline & Insulin dependency & $7(3.6)$ & $87(4.5)$ & $79(4.3)$ & \\
\hline & COPD & $5(2.6)$ & $103(5.3)$ & $45(2.4)$ & $<0.001$ \\
\hline & Relevant heart disease & $3(1.6)$ & $137(7.1)$ & $89(4.8)$ & $<0.001$ \\
\hline & Arterial hypertension requiring medication & $78(40.6)$ & $931(48.1)$ & $836(45.0)$ & 0.042 \\
\hline & Peripheral arterial disease & $1(0.5)$ & $22(1.1)$ & $10(0.5)$ & 0.11 \\
\hline & Dialysis & 0 & $7(0.4)$ & $4(0.2)$ & 0.52 \\
\hline & Central nervous system disease & $8(4.2)$ & $122(6.3)$ & $57(3.1)$ & $<0.001$ \\
\hline & \multicolumn{5}{|l|}{ Number of comorbidities } \\
\hline & 0 & $110(57.3)$ & $863(44.6)$ & $914(49.2)$ & 0.001 \\
\hline & 1 & $54(28.1)$ & $659(34.1)$ & $618(33.3)$ & \\
\hline & $\geq 2$ & $28(14.6)$ & $412(21.3)$ & $325(17.5)$ & \\
\hline & Dyspnea & $8(4.2)$ & $291(15.0)$ & $142(7.6)$ & $<0.001$ \\
\hline & Weight loss $>10 \%$ in the last 6 months & $20(10.4)$ & $307(15.9)$ & $80(4.3)$ & $<0.001$ \\
\hline & \multicolumn{5}{|l|}{ ASA } \\
\hline & $1-2$ & $72(37.5)$ & $685(35.4)$ & $541(29.1)$ & $<0.001$ \\
\hline & $\geq 3$ & $120(62.5)$ & $1,247(64.5)$ & $1,316(70.9)$ & \\
\hline & Unknown & 0 & $2(0.1)$ & 0 & \\
\hline & \multicolumn{5}{|l|}{ Hypoalbuminemia $(<3.0 \mathrm{~g} / \mathrm{dl})$} \\
\hline & Yes & $4(2.1)$ & $285(14.7)$ & $37(2.0)$ & $<0.001$ \\
\hline & No & $156(81.3)$ & $1,245(64.4)$ & $1,550(83.5)$ & \\
\hline & Unknown & $32(16.7)$ & $404(20.9)$ & $270(14.5)$ & \\
\hline & \multicolumn{5}{|l|}{ Hypercreatinemia $(>1.5 \mathrm{mg} / \mathrm{dl})$} \\
\hline & Yes & $4(2.1)$ & $68(3.5)$ & $54(2.9)$ & 0.60 \\
\hline & No & $182(94.8)$ & $1,794(92.8)$ & $1,743(93.9)$ & \\
\hline & Missing & $6(3.1)$ & $72(3.7)$ & $60(3.2)$ & \\
\hline $\begin{array}{l}S C L R \text { simultaneous colorectal } \\
\text { and liver resection }\end{array} R$ colorec- & \multicolumn{5}{|c|}{ Anemia (hematocrit $<36.1 \%$ for males, $<40.7 \%$ for females) } \\
\hline tal resection, $L R$ liver resection & Yes & $99(51.6)$ & $1,301(67.2)$ & 759 (40.9) & $<0.001$ \\
\hline
\end{tabular}

SCLR simultaneous colorectal and liver resection, $C R$ colorectal resection, $L R$ liver resection 
Table 1 (continued)

\begin{tabular}{lcccc}
\hline & SCLR & CR & LR & $p$-value overall \\
\hline No & $89(46.3)$ & $587(30.4)$ & $1,060(57.1)$ & \\
Missing & $4(2.1)$ & $46(2.4)$ & $38(2.0)$ & \\
Hyponatremia $(<136 \mathrm{mmol} / \mathrm{L})$ & & & & \\
Yes & $13(6.8)$ & $251(13.0)$ & $108(5.8)$ & $<0.001$ \\
No & $169(88.0)$ & $1,591(82.3)$ & $1,660(89.4)$ & \\
Missing & $10(5.2)$ & $92(4.8)$ & $89(4.8)$ & \\
\hline
\end{tabular}

0.40 , CI: $0.24-0.66, p<0.001$ ), while the sum of the predicted risks of CR and LR was similar to SCLR for both complications. The risk of having at least one complication was lower in CR (OR: 0.58, CI: 0.41-0.84, $p=0.004$ ) and LR (OR: 0.42, CI: 0.29-0.61, $p<0.001$ ) compared to SCLR, while the use of intraoperative red blood cells was significantly lower in CR (OR: $0.41, \mathrm{CI}: 0.27-0.61, p<0.001)$ than SCLR but similar to LR (OR: 1.08, CI: 0.73-1.61, $p=0.59$ ). The adjusted predicted risks for the number of adverse perioperative outcomes are presented in Table 4. Patients undergoing SCLR have a predicted risk of at least one complication of $36.29 \%$; this risk is lower for CR (26.61\%) and LR (19.82\%), while their sum is bigger than that for SCLR. After adjustment, the median operation time was longer in SCLR (273 min, CI: 253-295) than in CR (172, CI: 168-177) and LR (222, CI: 217-228) patients, $p<0.001$ for both comparisons (Table 3). Length of hospital stay was longest in SCLR (9.54 days, CI: 8.75-10.40) and shorter in CR (8.10, CI: 7.87-8.34) and LR (6.43, CI: 6.25-6.62), $p<0.001$ for both comparisons.

\section{Subgroup Analyses by Major and Minor Hepatectomy}

In adjusted analyses, patients undergoing major hepatectomy in the LR group had a lower risk of having any SSI (OR: 0.36 , CI: $0.18-0.73, p=0.005)$ and at least one complication
Table 2 Comparison of frequencies of short-term postoperative complications among patients undergoing SCLR, CR, and LR
SCLR simultaneous colorectal and liver resection, $C R$ colorectal resection, $L R$ liver resection, SSI surgical site infection, CNS central nervous system, $D V T$ deep venous thrombosis

\begin{tabular}{|c|c|c|c|c|}
\hline & SCLR & $\mathrm{CR}$ & LR & $p$-value \\
\hline Superficial SSI & $14(7.3)$ & $168(8.7)$ & $79(4.3)$ & $<0.001$ \\
\hline Deep incisional SSI & $19(9.9)$ & $78(4.0)$ & $24(1.3)$ & $<0.001$ \\
\hline Organ space SSI & $24(12.5)$ & $100(5.2)$ & $95(5.1)$ & $<0.001$ \\
\hline Any SSI & $48(25.0)$ & $305(15.8)$ & $187(10.1)$ & $<0.001$ \\
\hline Cardiopulmonary complication & $19(9.9)$ & $120(6.2)$ & $108(5.8)$ & 0.08 \\
\hline Renal complication & $15(7.8)$ & $129(6.7)$ & $85(4.6)$ & 0.01 \\
\hline CNS complication & 0 & $17(0.9)$ & $8(0.4)$ & 0.12 \\
\hline DVT/pulmonary embolism & $7(3.6)$ & $59(3.1)$ & $45(2.4)$ & 0.38 \\
\hline Septic complication & $26(13.5)$ & $173(8.9)$ & $133(7.2)$ & 0.004 \\
\hline At least one complication & $70(36.5)$ & $540(27.9)$ & $375(20.2)$ & $<0.001$ \\
\hline \multicolumn{5}{|c|}{ Number of individual complications } \\
\hline 0 & $121(63.0)$ & $1,379(71.3)$ & $1,472(79.3)$ & \multirow[t]{7}{*}{$<0.001$} \\
\hline 1 & $38(19.8)$ & $334(17.3)$ & $239(12.9)$ & \\
\hline 2 & $15(7.8)$ & $126(6.5)$ & $76(4.1)$ & \\
\hline 3 & $7(3.7)$ & $52(2.7)$ & $26(1.4)$ & \\
\hline 4 & $6(3.1)$ & $20(1.0)$ & $26(1.4)$ & \\
\hline 5 & $1(0.5)$ & $9(0.5)$ & $12(0.6)$ & \\
\hline$\geq 6$ & $4(2.1)$ & $14(0.7)$ & $6(0.3)$ & \\
\hline \multicolumn{5}{|l|}{ Use of red blood cells } \\
\hline No & $139(72.4)$ & $1,627(84.1)$ & $1,405(75.7)$ & \multirow[t]{3}{*}{$<0.001$} \\
\hline Yes & $53(27.6)$ & $305(15.8)$ & $452(24.3)$ & \\
\hline Unknown & 0 & $2(0.1)$ & 0 & \\
\hline Return to operating room & $10(5.2)$ & $155(8.0)$ & $70(3.8)$ & $<0.001$ \\
\hline Mortality & $2(1.0)$ & $89(4.6)$ & $23(1.2)$ & $<0.001$ \\
\hline
\end{tabular}


(OR: 0.50 , CI: $0.27-0.93, p=0.03$ ) compared to SCLR patients (Table 5). Adjusted median length of hospital stay and median length of operation were longer in SCLR patients than in LR patients (8.8 (CI: 7.6-10.1) versus 6.8 (CI: 6.5-7.0) days, 321 (288-358) versus 259 (251-267) min, respectively). Among patients undergoing minor hepatectomies, SCLR had higher odds for any SSI, septic complications, and at least one complication. The duration of hospital stay and length of operation were longer in SCLR than in LR patients (Table 5).

Predictors of Adverse Outcomes Among SCLR Patients

In adjusted analyses, the only significant predictor of at least one postoperative complication was any comorbidity (OR: 3.29, CI: $1.65-6.53, p=0.001)$. All other potential predictors did not show a significant association with adverse postoperative complications, including minor/major hepatectomy (OR: 1.11, CI: 0.57-2.15, $p=0.76$ ) (Table 6).

\section{Sensitivity Analysis}

The vast majority of the estimates did not significantly differ after excluding the laboratory values as covariates from the multivariable analyses. There were three results where the significance level changed. First, the adjusted odds ratio of superficial SSI comparing SCLR to LR was 0.53 (CI: 0.29$0.97, p=0.04)$; second, the adjusted odds ratio for return to operating room comparing SCLR to CR was 1.95 (CI: 0.94 4.07, $p=0.08$ ); and third, in the subgroup analysis of major hepatectomies, the odds ratio of any septic complication was 0.46 (CI: $0.21-0.98, p=0.046$ ).

\section{Discussion}

To our knowledge, this is the first large-scale study assessing perioperative outcomes among patients undergoing SCLR versus isolated CR and LR. Using the NSQIP dataset, this investigation provides strong evidence that patients undergoing SCLR have more perioperative adverse outcomes, longer operation times, and longer hospital stays than patients undergoing isolated CR and LR. The higher risk of perioperative adverse outcomes comparing SCLR and LR patients holds true for both major and minor hepatectomies, while the sum of adverse outcomes of CR and LR might be higher than those for SCLR. However, the comparison of the combination of CR and LR versus SCLR favors SCLR over the staged approach - a confirmation that SCLR is not only an attractive option but might rather be the treatment strategy of choice in selected patients.

In the contemporary management of patients with synchronous hepatic colorectal metastases, a growing body of 
Table 4 Results of adjusted analyses of the comparison of short-term postoperative complications among patients undergoing SCLR, CR, and LR including their predicted adjusted risks

\begin{tabular}{|c|c|c|c|c|c|c|c|}
\hline & \multicolumn{3}{|c|}{ Odds ratios $(95 \% \mathrm{CI})$} & \multirow[b]{2}{*}{$p$-value ${ }^{*}$} & \multicolumn{3}{|c|}{ Multivariable-adjusted predicted risks (\%) } \\
\hline & SCLR & $\mathrm{CR}$ & LR & & SCLR & $\mathrm{CR}$ & LR \\
\hline Superficial SSI & Ref. & $1.22(0.63-2.36)$ & $0.55(0.28-1.09)$ & $\begin{array}{l}0.56 \\
0.09\end{array}$ & 6.45 & 6.96 & 3.84 \\
\hline Deep incisional SSI & Ref. & $0.42(0.22-0.82)$ & $0.15(0.07-0.31)$ & $\begin{array}{c}0.01 \\
<0.001\end{array}$ & 7.34 & 3.22 & 1.10 \\
\hline Organ space SSI & Ref. & $0.41(0.24-0.69)$ & $0.31(0.18-0.52)$ & $\begin{array}{r}0.001 \\
<0.001\end{array}$ & 13.56 & 4.96 & 4.63 \\
\hline Any SSI & Ref. & $0.62(0.41-0.94)$ & $0.33(0.22-0.51)$ & $\begin{array}{r}0.025 \\
<0.001\end{array}$ & 23.24 & 14.34 & 9.38 \\
\hline Cardiopulmonary complication & Ref. & $0.38(0.21-0.68)$ & $0.47(0.26-0.83)$ & $\begin{array}{l}0.001 \\
0.009\end{array}$ & 9.89 & 4.86 & 4.96 \\
\hline Renal complication & Ref. & $0.59(0.31-1.10)$ & $0.53(0.28-1.00)$ & $\begin{array}{l}0.10 \\
0.05\end{array}$ & 7.74 & 5.28 & 4.14 \\
\hline CNS complication & N/A & N/A & N/A & N/A & N/A & N/A & N/A \\
\hline DVT/pulmonary embolism & Ref. & $0.72(0.28-1.91)$ & $0.72(0.27-1.90)$ & $\begin{array}{l}0.52 \\
0.51\end{array}$ & 2.93 & 2.73 & 2.27 \\
\hline Septic complication & Ref. & $0.43(0.26-0.71)$ & $0.40(0.24-0.66)$ & $\begin{array}{r}0.001 \\
<0.001\end{array}$ & 14.62 & 7.97 & 6.74 \\
\hline At least one complication & Ref. & $0.58(0.41-0.84)$ & $0.42(0.29-0.61)$ & $\begin{array}{r}0.004 \\
<0.001\end{array}$ & 36.29 & 26.61 & 19.82 \\
\hline \multicolumn{8}{|l|}{ Number of complications } \\
\hline 0 & & & & 0.001 & 65.46 & 73.42 & 77.56 \\
\hline 1 & & & & $<0.001$ & 17.20 & 15.76 & 14.58 \\
\hline 2 & & & & & 7.72 & 5.84 & 4.74 \\
\hline 3 & & & & & 3.99 & 2.53 & 1.79 \\
\hline 4 & & & & & 2.22 & 1.19 & 0.74 \\
\hline 5 & & & & & 1.29 & 0.59 & 0.32 \\
\hline$\geq 6$ & & & & & 0.77 & 0.30 & 0.14 \\
\hline Use of intraop red blood cell products & Ref. & $0.41(0.27-0.61)$ & $1.08(0.73-1.61)$ & $\begin{array}{c}<0.001 \\
0.69\end{array}$ & 25.41 & 15.10 & 24.56 \\
\hline Return to OR & Ref. & $2.78(1.11-6.99)$ & $1.08(0.42-2.75)$ & $\begin{array}{l}0.03 \\
0.88\end{array}$ & 3.12 & 7.85 & 3.60 \\
\hline Mortality & $\mathrm{N} / \mathrm{A}$ & $\mathrm{N} / \mathrm{A}$ & $\mathrm{N} / \mathrm{A}$ & N/A & $\mathrm{N} / \mathrm{A}$ & N/A & $\mathrm{N} / \mathrm{A}$ \\
\hline
\end{tabular}

SCLR simultaneous colorectal and liver resection, $C R$ colorectal resection, $L R$ liver resection * (1) value: SCLR vs. CR, (2) value: SCLR vs. LR. Adjustment performed for gender, ethnicity, age, BMI, smoking status, comorbidity, dyspnoe, ASA score, preoperative weight loss, preoperative radio-/chemotherapy, hypoalbuminemia, hypercreatinemia, anemia, hyponatremia. N/A: not applicable for adjusted analysis due to low frequency in the SCLR group

literature supports a multimodality approach whereby patients undergo resection of primary and metastatic sites, systemic therapy, and, in selected patients, radiotherapy. ${ }^{9,10,22-27}$ The appropriate timing of the various interventions is a topic of significant debate. The classical therapeutical pathway to this disease foresees patients first undergoing the primary tumor resection (in rectal patients following chemoradiation) followed by systemic therapy of an arbitrary duration, typically 6 months or longer. In this classical pathway, resection of hepatic metastases is then performed only if the indication for resection remains. A growing body of literature suggests that alternative approaches may be reasonable. ${ }^{10,15,18,27} \mathrm{~A}$ number of authors have suggested that the hepatic metastases are to be prioritized over minimally symptomatic primary tumors and that early interventions should be focused on achieving complete extirpation of the hepatic metastases. ${ }^{28,29}$ For many patients, especially those with marginally resectable hepatic metastases and those with significant hepatic tumor burdens, the initial intervention should be contemporary multidrug systemic therapy. ${ }^{30}$ The observation that patients with non-resectable metastatic disease do not need to have their primary tumors resected as a matter of routine supports this 


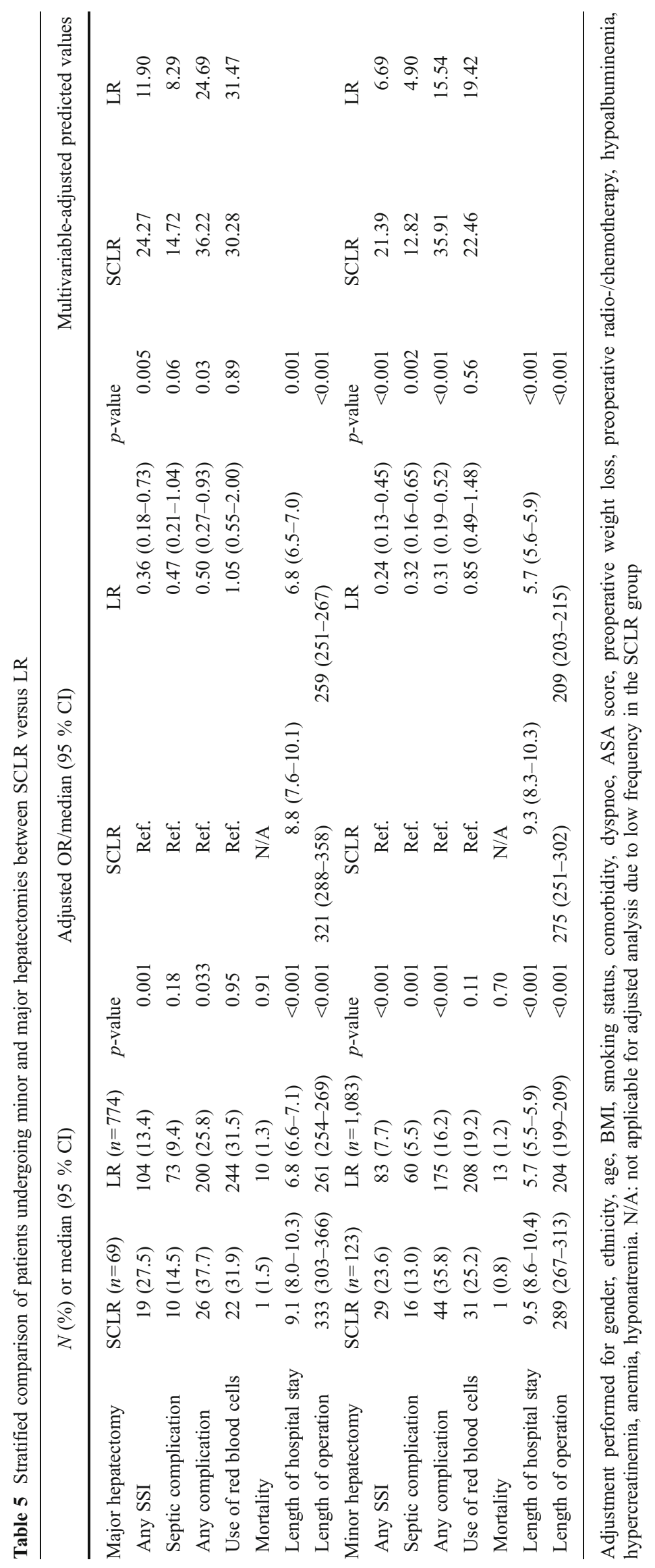


Table 6 Predictors of at least one complication among patients undergoing SCLR

\begin{tabular}{|c|c|c|c|c|c|c|}
\hline & $\begin{array}{l}\text { No postoperative complications } \\
(n=112,63.5 \%)\end{array}$ & $\begin{array}{l}\text { At least one postoperative } \\
\text { complication }(n=70,36.5 \%)\end{array}$ & $\begin{array}{l}\text { Unadjusted OR } \\
(95 \% \mathrm{CI})\end{array}$ & $\begin{array}{l}p \text { - } \\
\text { value }\end{array}$ & $\begin{array}{l}\text { Multivariable-adjusted } \\
\text { OR }(95 \% \mathrm{CI})\end{array}$ & $\begin{array}{l}p \text { - } \\
\text { value }\end{array}$ \\
\hline $\begin{array}{l}\text { Minor } \\
\text { hepatecto- } \\
\text { my }\end{array}$ & $79(64.2)$ & $44(35.8)$ & Ref. & 0.79 & Ref. & 0.76 \\
\hline $\begin{array}{l}\text { Major } \\
\text { hepatecto- } \\
\text { my }\end{array}$ & $43(62.3)$ & $26(37.7)$ & $1.09(0.59-2.00)$ & & $1.11(0.57-2.15)$ & \\
\hline \multicolumn{7}{|l|}{ Gender } \\
\hline Male & $73(59.8)$ & $45(64.3)$ & Ref. & 0.54 & Ref. & 0.40 \\
\hline Female & $49(40.2)$ & $25(25.7)$ & $0.83(0.45-1.52)$ & & $0.74(0.37-1.49)$ & \\
\hline \multicolumn{7}{|l|}{ Ethnicity } \\
\hline White & $97(79.5)$ & $54(77.1)$ & Ref. & 0.48 & Ref. & \\
\hline Black & $7(5.7)$ & $8(11.4)$ & $2.05(0.71-5.97)$ & & $2.57(0.82-8.04)$ & 0.11 \\
\hline Hispanic & $3(2.5)$ & $2(2.9)$ & $1.20(0.19-7.39)$ & & $1.37(0.18-10.22)$ & 0.76 \\
\hline $\begin{array}{l}\text { Other/ } \\
\text { missing }\end{array}$ & $15(12.3)$ & $6(8.6)$ & $0.72(0.26-1.96$ & & $0.94(0.32-2.74)$ & 0.90 \\
\hline \multicolumn{7}{|l|}{ Age } \\
\hline$\leq 65$ years & $91(74.6)$ & $53(75.7)$ & Ref. & 0.86 & Ref. & 0.59 \\
\hline$>65$ years & $31(25.4)$ & $17(24.3)$ & $0.94(0.48-1.86)$ & & $0.81(0.37-1.76)$ & \\
\hline \multicolumn{7}{|l|}{ BMI } \\
\hline$<26 \mathrm{~kg} / \mathrm{m}^{2}$ & $57(46.7)$ & $33(47.1)$ & Ref. & 0.96 & Ref. & 0.53 \\
\hline$\geq 26 \mathrm{~kg} / \mathrm{m}^{2}$ & $65(53.3)$ & $37(52.9)$ & $0.98(0.55-1.77)$ & & $0.80(0.40-1.60)$ & \\
\hline \multicolumn{7}{|c|}{ Smoking status } \\
\hline No & $90(73.8)$ & $51(72.9)$ & Ref. & 0.89 & Ref. & 0.30 \\
\hline Yes & $32(26.2)$ & $19(27.1)$ & $1.05(0.54-2.03)$ & & $0.67(0.32-1.43)$ & \\
\hline \multicolumn{7}{|l|}{ Comorbidity } \\
\hline 0 & $95(77.9)$ & $43(61.4)$ & Ref. & $<0.001$ & Ref. & 0.001 \\
\hline$\geq 1$ & $27(22.1)$ & $27(38.6)$ & $3.05(1.67-5.66)$ & & $3.29(1.65-6.53)$ & \\
\hline \multicolumn{7}{|l|}{ Dyspnea } \\
\hline No & $119(97.5)$ & $65(92.7)$ & Ref. & 0.12 & Ref. & 0.39 \\
\hline Yes & $3(2.5)$ & $5(7.1)$ & $3.05(0.71-13.2)$ & & $1.98(0.41-9.59)$ & \\
\hline \multicolumn{7}{|l|}{ ASA } \\
\hline $1-2$ & $49(40.2)$ & $23(32.9)$ & Ref. & 0.31 & Ref. & 0.87 \\
\hline$\geq 3$ & $73(59.8)$ & $47(67.1)$ & $1.37(0.74-2.54)$ & & $1.06(0.53-2.12)$ & \\
\hline \multicolumn{7}{|c|}{ Preoperative weight loss } \\
\hline No & $109(89.3)$ & $63(90.0)$ & Ref. & 0.89 & Ref. & 0.71 \\
\hline Yes & $13(10.7)$ & $7(10.0)$ & $0.93(0.35-2.46)$ & & $0.81(0.28-2.36)$ & \\
\hline \multicolumn{7}{|c|}{ Preoperative radiotherapy } \\
\hline No & $95(77.9)$ & $57(81.4)$ & Ref. & 0.56 & Ref. & 0.42 \\
\hline Yes & $27(22.1)$ & $13(18.6)$ & $0.80(0.38-1.68)$ & & $0.72(0.32-1.61)$ & \\
\hline \multicolumn{7}{|c|}{ Preoperative chemotherapy } \\
\hline No & $105(86.1)$ & $58(82.9)$ & Ref. & 0.55 & Ref. & 0.68 \\
\hline Yes & $17(13.9)$ & $12(17.1)$ & $1.28(0.57-2.86)$ & & $1.20(0.51-2.86)$ & \\
\hline
\end{tabular}

Adjustment performed for gender, ethnicity, age, BMI, smoking status, comorbidity, dyspnea, ASA score, preoperative weight loss, preoperative radio-/chemotherapy

prioritization. For many patients with synchronous hepatic metastases, the initial prioritization of the hepatic metastases will lead to situations where simultaneous hepatic resections may be considered. As a general summary, the existing literature from modest single or limited multiinstitutional studies suggests that the combined morbidity of staged colorectal and hepatic resections is greater than simultaneous resections, especially in patients requiring lower complexity 
hepatic procedures. ${ }^{10,27}$ From an oncologic perspective, there often exists a perception that patients with synchronous metastases are at greater risk for early progression following partial hepatectomy and, for that reason, should only undergo hepatic resection following extended periods of selection with systemic therapy. Recent studies have reported that the overall 5 -year survival rates for patients undergoing SCLR at highvolume centers are as high as $53 \%$, which is comparable to a completed staged approach of isolated CR and LR. ${ }^{15-19,31-34}$ Nonetheless, whether the experiences of high-volume centers as described in these limited reports can be generalized across a larger population of patients is not clear especially in light of the fact that the incidence of postoperative complications after liver resections appears to be directly correlated with overall survival $\left[^{5}\right]$.

Our analysis shows that adverse short-term complications among hospitals reporting to NSQIP are substantially higher for patients undergoing SCLR than for patients undergoing isolated LR. This is in contrast to many other single-center investigations which report that SCLR has similar if not lower postoperative complication rates compared to LR, ${ }^{15,16,18,32,35,36}$ while a minority also showed higher postoperative adverse outcomes for patients undergoing SCLR than LR alone. ${ }^{10,17}$

However, the comparison of SCLR should not be only to LR, but the entire staged treatment regimen. Comparing the predicted estimates of complications from CR and LR together versus the predicted complications of SCLR demonstrates that SCLR fares better in several outcomes measures. This finding is supported by previous studies. ${ }^{10,35,36} \mathrm{Be}$ cause NSQIP data do not contain patient identifiers, it is not possible to directly combine patients undergoing CR and LR to create a patient subset of staged resection. However, pooling of the multivariable-adjusted predicted estimates for CR and LR allows an informal comparison of CR and LR to SCLR. This approach might even have substantial benefits over the pure comparison of SCLR to the staged procedure since it likely includes also patients who were planned to undergo a staged treatment but did not successfully complete both surgeries for one of the following reasons: patients whose overall condition after CR did not allow performing LR, patients with tumor progression not enabling a complete tumor resection anymore, or patients died before the planned liver resection. Only including patients completing CR and LR might lead to a substantial selection bias favoring the staged procedure since only patients with an advantageous disease progression and beneficial recovery after CR will undergo LR at a later time-point. ${ }^{37}$ However, if including those patients to the comparator group for SCLR would even lead to a survival benefit for SCLR remains highly speculative.

In early experiences of SCLR, patients were more apt to be limited to right-sided colectomies and minor hepatectomies. ${ }^{38}$
In more contemporary experiences, left-sided colectomies and rectal resections and major hepatectomies are described in greater frequency with excellent outcomes. ${ }^{16}$ However, Reddy et al. suggested in a multiinstitutional analysis that patients undergoing SCLR only benefit from this simultaneous approach if a minor simultaneous hepatectomy is performed. In their report, patients requiring more complex hepatectomies ( $\geq 3$ segments) experienced more postoperative adverse outcomes than patients undergoing the staged approach. ${ }^{10}$ Our results suggest that SCLR has significantly more adverse outcomes than isolated LR for both minor and major hepatectomies. However, comparing the results of the predicted combined risks for staged CR and LR versus SCLR suggests an increased overall complication rate that is higher for the staged approach even when more complex procedures are involved. The fact that only one patient $(1.5 \%)$ died undergoing SCLR with major hepatectomy highlights that this procedure can be performed safely. In other analyses, however, major hepatectomy in SCLR was a significant predictor of mortality, ${ }^{10,32,39}$ but not in others. ${ }^{16,17,36,40}$ In sum, our results suggest that SCLR can be recommended in carefully selected patients undergoing both major and minor hepatectomies. What is not clear though is how to best select candidates for SCLR. The authors would readily admit that SCLR is not appropriate for all patients requiring complex hepatic and/or colorectal resections. Nonetheless, in patients where the complex procedures appear to be relatively straightforward, SCLR should be considered.

There are a number of limitations that should be acknowledged. First, using the NSQIP dataset, it is only possible to identify patients with secondary cancers to the liver, but it is not possible to further limit those patients with colorectal metastasis. However, the majority of liver resections performed for secondary cancers are performed due to colorectal liver metastasis. Second, because patient identifiers are missing in NSQIP, it is also not possible to track patients over time. It is therefore not possible to distinguish between synchronous and metachronous liver metastasis. However, 30day postoperative outcomes might not differ if a patient undergoes a liver resection for either underlying disease. Given our inability to track patients over time, the sum of complications of CR and LR can only be considered an approximation of what could be expected as the total number of complications if a staged approach were to be planned. Third, complication severity is not captured in the NSQIP dataset. It is therefore possible that any of one group might have had complications that were more severe than their counterparts. Finally, due to the retrospective nature of the analysis, we were limited to the covariates available in the dataset and additional confounding cannot be ruled out. 


\section{Conclusion}

Among hospitals reporting outcomes to NSQIP, the risk of 30-day adverse outcomes for SCLR is significantly higher than that for CR and LR. The expected combined morbidities of staged procedures though likely favors SCLR in carefully selected patients undergoing even complex hepatic and colorectal resections and should be considered. Further studies addressing the long-term outcomes of this approach are necessary to ensure its proper role in the management of these complex patients.

Acknowledgment The American College of Surgeons National Surgical Quality Improvement Program and the hospitals participating in the ACS NSQIP are the source of the data used herein; they have not verified and are not responsible for the statistical validity of the data analysis or the conclusions derived by the authors.

\section{References}

1. Siegel R, Naishadham D, Jemal A. Cancer statistics, 2012. CA Cancer J Clin 2012;62:10-29.

2. Galandiuk S, Wieand HS, Moertel CG, Cha SS, Fitzgibbons RJ, Jr., Pemberton JH, Wolff BG. Patterns of recurrence after curative resection of carcinoma of the colon and rectum. Surg Gynecol Obstet 1992;174:27-32.

3. Weiss L, Grundmann E, Torhorst J, Hartveit F, Moberg I, Eder M, Fenoglio-Preiser CM, Napier J, Horne CH, Lopez MJ, et al. Haematogenous metastatic patterns in colonic carcinoma: an analysis of 1541 necropsies. J Pathol 1986;150:195-203.

4. Poon MA, O'Connell MJ, Moertel CG, Wieand HS, Cullinan SA, Everson LK, Krook JE, Mailliard JA, Laurie JA, Tschetter LK, et al. Biochemical modulation of fluorouracil: evidence of significant improvement of survival and quality of life in patients with advanced colorectal carcinoma. J Clin Oncol 1989;7:1407-1418.

5. Schiesser M, Chen JW, Maddern GJ, Padbury RT. Perioperative morbidity affects long-term survival in patients following liver resection for colorectal metastases. J Gastrointest Surg 2008;12:1054-1060.

6. Fong Y, Fortner J, Sun RL, Brennan MF, Blumgart LH. Clinical score for predicting recurrence after hepatic resection for metastatic colorectal cancer: analysis of 1001 consecutive cases. Ann Surg 1999;230:309-318; discussion 318-321.

7. Choti MA, Sitzmann JV, Tiburi MF, Sumetchotimetha W, Rangsin $\mathrm{R}$, Schulick RD, Lillemoe KD, Yeo CJ, Cameron JL. Trends in long-term survival following liver resection for hepatic colorectal metastases. Ann Surg 2002;235:759-766.

8. Vigano L, Ferrero A, Lo Tesoriere R, Capussotti L. Liver surgery for colorectal metastases: results after 10 years of follow-up. Longterm survivors, late recurrences, and prognostic role of morbidity. Ann Surg Oncol 2008;15:2458-2464.

9. Abdalla EK, Vauthey JN, Ellis LM, Ellis V, Pollock R, Broglio KR, Hess K, Curley SA. Recurrence and outcomes following hepatic resection, radiofrequency ablation, and combined resection/ablation for colorectal liver metastases. Ann Surg 2004;239:818-825; discussion 825-817.

10. Reddy SK, Pawlik TM, Zorzi D, Gleisner AL, Ribero D, Assumpcao L, Barbas AS, Abdalla EK, Choti MA, Vauthey JN, Ludwig KA, Mantyh CR, Morse MA, Clary BM. Simultaneous resections of colorectal cancer and synchronous liver metastases: a multiinstitutional analysis. Ann Surg Oncol 2007;14:3481-3491.
11. Benzoni E, Cojutti A, Lorenzin D, Adani GL, Baccarani U, Favero A, Zompicchiati A, Bresadola F, Uzzau A. Liver resective surgery: a multivariate analysis of postoperative outcome and complication. Langenbecks Arch Surg 2007;392:45-54.

12. Imamura H, Seyama Y, Kokudo N, Maema A, Sugawara Y, Sano K, Takayama T, Makuuchi M. One thousand fifty-six hepatectomies without mortality in 8 years. Arch Surg 2003;138:1198-1206; discussion 1206

13. Poon RT, Fan ST, Lo CM, Liu CL, Lam CM, Yuen WK, Yeung C, Wong J. Improving perioperative outcome expands the role of hepatectomy in management of benign and malignant hepatobiliary diseases: analysis of 1222 consecutive patients from a prospective database. Ann Surg 2004;240:698-708; discussion 708-610.

14. Kohn GP, Nikfarjam M. The effect of surgical volume and the provision of residency and fellowship training on complications of major hepatic resection. J Gastrointest Surg 2010;14:1981-1989.

15. Lyass S, Zamir G, Matot I, Goitein D, Eid A, Jurim O. Combined colon and hepatic resection for synchronous colorectal liver metastases. J Surg Oncol 2001;78:17-21.

16. Weber JC, Bachellier P, Oussoultzoglou E, Jaeck D. Simultaneous resection of colorectal primary tumour and synchronous liver metastases. Br J Surg 2003;90:956-962.

17. Tanaka K, Shimada H, Matsuo K, Nagano Y, Endo I, Sekido H, Togo S. Outcome after simultaneous colorectal and hepatic resection for colorectal cancer with synchronous metastases. Surgery 2004;136:650-659.

18. Chua HK, Sondenaa K, Tsiotos GG, Larson DR, Wolff BG, Nagorney DM. Concurrent vs. staged colectomy and hepatectomy for primary colorectal cancer with synchronous hepatic metastases. Dis Colon Rectum 2004;47:1310-1316.

19. Slupski M, Wlodarczyk Z, Jasinski M, Masztalerz M, Tujakowski J. Outcomes of simultaneous and delayed resections of synchronous colorectal liver metastases. Can J Surg 2009;52:E241-244.

20. Morris EJ, Forman D, Thomas JD, Quirke P, Taylor EF, Fairley L, Cottier B, Poston G. Surgical management and outcomes of colorectal cancer liver metastases. Br J Surg 2010;97:1110-1118.

21. Rutten-van Molken MP, van Doorslaer EK, van Vliet RC. Statistical analysis of cost outcomes in a randomized controlled clinical trial. Health Econ 1994;3:333-345.

22. Saltz LB, Clarke S, Diaz-Rubio E, Scheithauer W, Figer A, Wong R, Koski S, Lichinitser M, Yang TS, Rivera F, Couture F, Sirzen F, Cassidy J. Bevacizumab in combination with oxaliplatin-based chemotherapy as first-line therapy in metastatic colorectal cancer: a randomized phase III study. J Clin Oncol 2008;26:2013-2019.

23. Peeters M, Price TJ, Cervantes A, Sobrero AF, Ducreux M, Hotko Y, Andre T, Chan E, Lordick F, Punt CJ, Strickland AH, Wilson G, Ciuleanu TE, Roman L, Van Cutsem E, Tzekova V, Collins S, Oliner KS, Rong A, Gansert J. Randomized phase III study of panitumumab with fluorouracil, leucovorin, and irinotecan (FOLFIRI) compared with FOLFIRI alone as second-line treatment in patients with metastatic colorectal cancer. J Clin Oncol 2010;28:4706-4713.

24. Lehmann K, Rickenbacher A, Weber A, Pestalozzi BC, Clavien PA. Chemotherapy before liver resection of colorectal metastases: friend or foe? Ann Surg 2012;255:237-247.

25. http://www.ncen.org/. Last accessed 07/2012.

26. Mulcahy MF, Lewandowski RJ, Ibrahim SM, Sato KT, Ryu RK, Atassi B, Newman S, Talamonti M, Omary RA, Benson A, 3rd, Salem R. Radioembolization of colorectal hepatic metastases using yttrium-90 microspheres. Cancer 2009;115:1849-1858.

27. Reddy SK, Zorzi D, Lum YW, Barbas AS, Pawlik TM, Ribero D, Abdalla EK, Choti MA, Kemp C, Vauthey JN, Morse MA, White RR, Clary BM. Timing of multimodality therapy for resectable synchronous colorectal liver metastases: a retrospective multi-institutional analysis. Ann Surg Oncol 2009;16:1809-1819. 
28. Martin R, Paty P, Fong Y, Grace A, Cohen A, DeMatteo R, Jarnagin W, Blumgart L. Simultaneous liver and colorectal resections are safe for synchronous colorectal liver metastasis. J Am Coll Surg 2003;197:233-241; discussion 241-232.

29. Mentha G, Majno PE, Andres A, Rubbia-Brandt L, Morel P, Roth AD. Neoadjuvant chemotherapy and resection of advanced synchronous liver metastases before treatment of the colorectal primary. Br J Surg 2006;93:872-878.

30. de Jong MC, van Dam RM, Maas M, Bemelmans MH, Olde Damink SW, Beets GL, Dejong CH. The liver-first approach for synchronous colorectal liver metastasis: a 5-year single-centre experience. HPB (Oxford) 2011;13:745-752.

31. Folprecht G, Grothey A, Alberts S, Raab HR, Kohne CH. Neoadjuvant treatment of unresectable colorectal liver metastases: correlation between tumour response and resection rates. Ann Oncol 2005;16:1311-1319.

32. de Santibanes E, Fernandez D, Vaccaro C, Quintana GO, Bonadeo F, Pekolj J, Bonofiglio C, Molmenti E. Short-term and long-term outcomes after simultaneous resection of colorectal malignancies and synchronous liver metastases. World J Surg 2010;34:2133-2140.

33. Thelen A, Jonas S, Benckert C, Spinelli A, Lopez-Hanninen E, Rudolph B, Neumann U, Neuhaus P. Simultaneous versus staged liver resection of synchronous liver metastases from colorectal cancer. Int J Colorectal Dis 2007;22:1269-1276.
34. Nakajima K, Takahashi S, Saito N, Kotaka M, Konishi M, Gotohda N, Kato Y, Kinoshita T. Predictive Factors for Anastomotic Leakage after Simultaneous Resection of Synchronous Colorectal Liver Metastasis. J Gastrointest Surg 2012 Apr;16(4):821-7.

35. Chen J, Li Q, Wang C, Zhu H, Shi Y, Zhao G. Simultaneous vs. staged resection for synchronous colorectal liver metastases: a metaanalysis. Int J Colorectal Dis 2011;26:191-199.

36. Capussotti L, Ferrero A, Vigano L, Ribero D, Lo Tesoriere R, Polastri R. Major liver resections synchronous with colorectal surgery. Ann Surg Oncol 2007;14:195-201.

37. de Haas RJ, Adam R, Wicherts DA, Azoulay D, Bismuth H, Vibert E, Salloum C, Perdigao F, Benkabbou A, Castaing D. Comparison of simultaneous or delayed liver surgery for limited synchronous colorectal metastases. Br J Surg 2010;97:1279-1289.

38. Cain KC, Harlow SD, Little RJ, Nan B, Yosef M, Taffe JR, Elliott MR. Bias due to left truncation and left censoring in longitudinal studies of developmental and disease processes. Am J Epidemiol 2011;173:1078-1084.

39. Jaeck D, Bachellier P, Weber JC, Boudjema K, Mustun A, Paris F, Schaal JC, Wolf P. [Surgical strategy in the treatment of synchronous hepatic metastases of colorectal cancers. Analysis of a series of 59 operated on patients]. Chirurgie 1999;124:258-263.

40. Bolton JS, Fuhrman GM. Survival after resection of multiple bilobar hepatic metastases from colorectal carcinoma. Ann Surg 2000;231:743-751. 